\title{
O LEITOR CRÍTICO NA POESIA DE MANUEL GUSMÃO
}

\section{THE CRITICAL READER IN THE POETRY OF \\ MANUEL GUSMÃO}

Marleide Anchieta ${ }^{\star}$

\begin{abstract}
RESUMO
Na poesia de Manuel Gusmão, o leitor é convidado a participar ativamente das cenas de escrita e de leitura. Para o poeta-crítico, o ato de ler, entendido como prática política e emancipatória, é partilha da experiência estética e desenvolvimento de nossas instâncias sensível-cognitivas, além da aprendizagem do mundo fora e dentro do texto. Nesse sentido, nosso artigo pretende analisar a configuração do leitor crítico a partir de três aspectos presentes na referida poesia - ato de co-moção, construção epistemológica e tessitura errática de habitação. Com essa perspectiva, recorreremos às abordagens teórico-críticas de Roland Barthes, Jacques Rancière e Eduardo Prado Coelho.
\end{abstract}

PALAVRAS-CHAVE: Poesia portuguesa contemporânea; Manuel Gusmão; Leitor crítico.

\section{ABSTRACT}

In the poetry of Manuel Gusmão, the reader is invited to actively participate in writing and reading scenes. To the poet-critic, the act of reading, understood as emancipatory and political practice, is sharing the aesthetic experience and the development of our sensitive-cognitive instances, beyond the world learning outside and inside the text. In this sense, our article aims to examine the critical reader configuration from three aspects present in that poetry - act of co-motion, epistemological construction and erratic tissue habitation. With this perspective, we turn to the theoretical-critical of Roland Bathes, Jacques Rancière and Eduardo Prado Coelho.

KEYWORDS: Contemporary Portuguese poetry; Manuel Gusmão; Critical reader. 
Ou a movente mão em movimento, em movimentos exploratórios? A mão que se aventura em território adormecido? A mão que sonha o sentido...

Manuel Gusmão

Eisenstein, ao visitar as reflexões do crítico norte-americano John Lowes, comenta que cada palavra é permeada, assim como cada imagem é transformada, "pela intensidade da imaginação de um ato criativo instigante" (EISENSTEIN, 2002, p. 13). Para ele, a capacidade imaginativa nos permite misturar e combinar elementos verbo-visuais possivelmente desconexos e estabelecer diferentes conexões em nosso pensamento. O cineasta acredita que somos co-movidos por nossas montagens imaginárias, já que tendemos a aproximar elementos autônomos que, muitas vezes, emergem inesperadamente, além de relacioná-los e daí engendrar uma "terceira coisa”, um novo sentido (idem, p. 17). Frente a isso, ele destaca a condição dinâmica da obra de arte, na qual o espectador tem um papel fundamental que não se refere à recepção passiva "do resultado consumado de um determinado processo de criação", mas ao seu caráter participativo ao "organizar as imagens no sentimento e na mente" (ibidem, p. 21). Eisenstein, dessa forma, o insere no princípio dinâmico e vital da visualidade, retirando-o da "lógica embrutecedora" da mera e acrítica transmissão (RANCIÈRE, 2010, p. 23), ou seja, aquela que limita a visão do espectador ao que o realizador lhe dá a ver e reduz seus sentimentos à energia que o cineasta lhe comunica (idem, p. 23).

De acordo com Rancière, a emancipação daquele que assiste a um espetáculo se inicia quando se compreende que o olhar é também uma forma de ação crítica capaz de confirmar ou transformar aquilo que é visualizado. Nesse sentido, o espectador é também ativo, pois observa, seleciona, analisa, compara, interpreta, compõe seu próprio filme, "seu próprio poema, como, a seu modo, fazem os actores ou os dramaturgos, os realizadores, os bailarinos ou os performers" (ibidem, p. 23). Embora apaixonados pela obra, são reflexivos e, por isso, capazes de, ao mesmo tempo, assegurar certo distanciamento e evocar um desejo de proximidade (BAECQUE, 2010, p. 21), segundo afirma o crítico Antoine de Baecque.

Quando se menciona o ato de leitura, o movimento não é diferente. Com as "maviolas esferográficas" instauradas no "tecido ininterrupto" da memória, articulam-se montagens imprevisíveis e audaciosas (HELDER, 2006, p. 141) que entrecruzam espaços, tempos, ideias, repertórios textuais e imagéticos: "Das raízes do seu sonho guarda -/ memória que tacteia os ares/ - gravidade que a ergue intensa,/ explodindo sempre, nos céus sobrepostos/ de um século/ instantâneo." (GUSMÃO, 1990, p. 96). Através de metáforas, metonímias, elipses, símiles, entre outros recursos, os poetas abrem um leque de possibilidades significativas. Os leitores, de certa maneira, procuram os fios, escavam as camadas, a fim de construir e reinventar em sua mente 
os sentidos e as imagens que, muitas vezes, aparecem de forma descontínua e inusitada. Por esse viés, movem o olhar e ativamente compõem "seu próprio poema com os elementos do poema que tem à sua frente" (RANCIÈRE, 2010, p. 22), desmantelando as fronteiras entre os que veem e os que agem, entre os que sentem e os que pensam, entre o leitor e o autor.

Aliás, ler já pressupõe movimento. Nessa ação, temos os olhos a deambular pelas palavras, as mãos a co-mover os sentidos, o corpo a se envolver com o texto, o cérebro a realizar as prováveis ligações. Etimologicamente, a leitura também nos dá a ver uma mobilização crítica, visto que, segundo ressalta Eduardo Prado Coelho, "aquele que lê é aquele que escolhe, que vai colher na árvore dos textos os frutos escolhidos: ler é eleger, escolher as palavras que emergem do fio do discurso, dar-lhes o brilho e a cor que lhes convêm, e por isso todo o leitor é um eleitor [...]" (COELHO, 2001, p. 78). Ler é, portanto, uma prática política e emancipatória, pois, através dela, temos a capacidade de "colher com os olhos", de selecionar entre várias opções aquela que nos convém. Porém, não se trata de uma escolha qualquer. É uma busca pelos melhores frutos. Busca que organiza letras, palavras, textos, a fim de atribuir significados aos sujeitos e ao mundo que os cercam. Quando se elege conscientemente, pratica-se uma leitura dinâmica de seu contexto e procuram-se caminhos para reconstruí-lo. Por isso, todos devem ter garantido seu direito de eleger, seu direito de ler.

Se, em primeira instância, a leitura se relaciona com a intelectualidade, ou seja, o intelectual é o "inter-lĕgĕre", o que compreende suas escolhas, o que sabe distinguir bem as possibilidades; num outro viés, ela é atividade sensível. Não à toa, Barthes a associa a um ato prazeroso, a "uma prática confortável” "que contenta, enche, dá euforia" (BARTHES, 1987, p. 21). Ela produz um encontro com o texto, estabelece uma relação de intimidade com o que é lido e integra a corporeidade verbal ao corpo leitor: "Curtas e lábeis as mãos do corpo põem o ilimitado em frases" (GUSMÃO, 1996, p. 33). O crítico francês ainda reforça a ideia de que "as palavras têm sabor", lembrando-nos de que os termos "saber" e "sabor" possuem, em latim, a mesma etimologia ${ }^{1}$. Assim, ter um paladar apurado significava saber selecionar os sabores, cultivar o bom gosto. Por conseguinte, Barthes defende que "[n]a ordem do saber, para que as coisas se tornem o que são, o que foram, é necessário esse ingrediente, o sal das palavras" (BARTHES, 1978, p. 20). A leitura, então, propicia aos que leem "esse gosto das palavras que faz o saber profundo, fecundo" (idem, p. 21).

Vale ressaltar que a escrita de Manuel Gusmão mobiliza uma "razão apaixonada" - a poesia -, transformando o texto num espaço corpóreo da "paixão do inteligível" (COELHO, 2001, p. 79). Ela une, concomitantemente, saber e sabor. Partindo dessa imbricação, a leitura, na obra do referido poeta, leva-nos a pensar em três instâncias: um ato de co-moção, uma construção epistemológica e uma tessitura errática de habitação. São modos de selecionar o que se lê e vê com consciência, empenho e sensibilidade, o que torna o leitor o dileto do poeta, ou seja, o escolhido afe- 
tivamente a partilhar a experiência estética e a ser o copartícipe do gesto escritural. Desse modo, leitor e autor reúnem corpos verbais e redigem o diálogo na "legenda de um encontro, de uma imagem, de uma fotografia, o fotograma dilecto, a fotografia delida, a fotografia lida e relida na gramática da sua luz, no drama da sua memória, na elegância de um olhar silencioso, na repetição impossível do nome que a nomeia." (idem, p. 80).

Não há dúvidas de que as mãos de ambos co-movem os textos e nos propõem uma "fisiologia da leitura" (GUSMÃO, 2010, p. 117), uma vez que, ao adentrarem a organicidade e a dinâmica vital do trabalho poético, são motivadas por uma perturbação, um assombro e, então, movimentam-se, reconfiguram-se, transformam-se na medida em que leem e escrevem cada letra e cada imagem. Nessa cumplicidade e nesse "vagaroso amor", o poema se dá a ver na "radioscopia incerta" dos sentidos (OLIVEIRA, 2003, p. 199), num ritmo cardíaco de palpitações oscilantes. Lido/escrito pelas mãos co-movidas, "habita agora/ a fluidez do sangue:/ cada imagem de fora,/ presa ao fotograma que já foi,/ de glóbulo em glóbulo se destrói” (idem, p. 199) e se reconstrói.

Na poesia de Gusmão, o leitor cinéfilo e bibliófilo, que opera "uma renovação da sensibilidade e da atividade crítica” (BAECQUE, 2010, p. 29), aprende a olhar com a "paciência de uma desmedida lentidão" (COELHO, 2001, p. 82). Suas instâncias perceptivas são convidadas à desautomatização para que, assim, se visualize atentamente o processo verbo-visual e o inventário de mundos que a leitura lhe oferece: “[...] outros capítulos dessa história e dessa escrita hão-de vir, lentos e vertiginosos, implacáveis e exaltantes." (GUSMÃO, 1990, p. 35); “[...] depositando-se em movimento lento no leito dessas frases." (idem, p. 36); "Em plena biblioteca, ouvindo os cavalos numa lenta invasão, o leitor redobra de atenção; [...]" (ibidem, p. 37); "Respiram apenas, lenta a mente/ e é contudo uma doce ilusão pensar a um mesmo ritmo." (ibidem, p. 27). Não é por acaso que, em Ensaio sobre a cegueira, Saramago, através da voz de um personagem, aconselha-nos: “[...] acolha-se ao dito antigo, tinham razão os que diziam que a paciência é boa para a vista [...]" (SARAMAGO, 1995, p. 283). Nessa esteira, o poeta teoriza a composição imagética e, de certo modo, o próprio ato de leitura, instigando seu leitor a ler de-vagar, a desenvolver "o esforço paciente" (GUSMÃO, 1990, p. 33) e a desestabilizar seu olhar adaptado à indiscernibilidade visual contemporânea, ainda que para isso o deixe afetado pela cegueira. Essa afecção torna-se imprescindível para o encontro íntimo com o texto, pois o excesso de luz parece um empecilho para a mobilização dos sentidos: "Demasiada é a luz e por momentos tu és um clarão que cega." (GUSMÃO, 2004, p. 22). Dessa maneira, a obscuridade ${ }^{2}$, inicialmente impactante, gera uma relação de cumplicidade entre as mãos que tateiam as camadas do texto, ainda que numa tentativa de "ocupação hesitante e cautelosa do espaço literário" (COELHO, 2001, p. 80): “O leitor está cego: a luz cai sobre o olhar: as coisas vão nascendo minuciosas despertas e límpidas, [...]” (GUSMÃO, 1990, p. 33); “a luz cai... contra o olhar...: como o dia se fazia abria-se 
o mundo: tu." (idem, p. 33); "Fechas os olhos cegos e a dupla negação traz a teus pés/ um mar que é a negra onda: a porta fechada: a parede cega.// Depois dizes, dispões as mãos - esta última ilusão/ de que a vida responde - sobre os joelhos." (GUSMÃO, 2004, p. 14). Na busca de uma sabedoria proveniente dos olhos fechados, da percepção de uma "respiração nocturna" das palavras (HELDER, 2006, p. 109), autor e leitor experimentam a "razão sensível" e a sinestésica força da composição escritural:

O olhar ouve o que alguém escreve, silencioso e malevolente, disciplinadamente edificando essa ciência errática agora sua. O leitor abre e fecha como uma janela, não cessa de se abrir na respiração dessa luz emprestada, cresce como a árvore fronteira ao quarto, no jardim nocturno,

estende os ramos através da alma do escritor, esse sangue opaco que não seca, essa promessa inadiável que não se cumpre. E é uma chama. O leitor vacila, e então os actores atropelam-se nessa cabeça cansada e erguida com orgulho, desfazendo-se na luz que é demasiada para o dia.

Longe,

Pede perdão, comovidamente, sôfrego e perdido, sobre o teu corpo como um rio fechado.

(GUSMÃO, 1990, p.36)

Numa partilha co-movida, o ato de escrita apresenta-se indissociável do movimento de leitura, conforme poetizou o jovem português Daniel Faria: "Sabes, leitor, que estamos ambos na mesma página// [...] A magnólia estende contra a minha escrita a tua sombra/ E eu toco na sombra da magnólia como se pegasse na tua mão" (FARIA, 2009, p. 327). Partindo desse princípio, poeta e leitor são "personagens da linguagem" (ALVES, 2000, p. 289), já que se tornam outros, encenam subjetividades no espaço-tempo da construção poemática. Não à toa, Charles Baudelaire, no célebre poema "Au lecteur", já havia nos apontado a cúmplice teatralização que se desenvolve no âmbito textual: “C'est l'Ennui! - l'œil charge d'un pleur involontaire,/ Il rêve d'échafauds en fumant son houka./ Tu connais, lecteur, ce mostre délicat, / - Hypocrite lecteur, - mon semblable, - mon frère!"3 (BAUDELAIRE, 2006, p.112). Percebe-se, portanto, um fingimento fraternalmente assumido através da imagem do hipócrita, ou seja, do hypocrites, que, na Grécia Antiga, remetia àquele que atuava no teatro (o ator) (CUNHA, 2010, p. 339). Numa ótica pessoana, diríamos que são personae a desempenharem seus papéis no âmbito ficcional da cena poética. Ida Alves reitera essa ideia ao explicar que "a escrita é uma cena teatral e o poema um lugar de observação, onde se exercita a visão interior capaz de reconhecer os mundos que constituem a existência” (ALVES, 2000, p. 200).

Frente ao teatro de alterizações, o leitor impulsiona suas "mãos sem gente" (HELDER, 2006, p. 52), inserindo-as subjetivamente no corpo textual histórico que é o poema. Por esse motivo, na visão barthesiana, ele é "aquela personagem que está no palco (mesmo clandestinamente) [...]; sua escuta é dupla (e, portanto, virtualmente múltipla).” (BARTHES, 2004, p. 
41). Ele "produz, amontoa linguagens, deixa-se infinita e incansavelmente atravessar por elas: ele é essa travessia." (idem, p. 41). Nesse sentido, na poética de Gusmão, o leitor participa ativa e criticamente na reinvenção dos procedimentos textuais - "O leitor, fechado nos parênteses, lê o capítulo em branco, a respiração da cidade submarina de onde os rios se precipitam e se cruzam desviados aqui" (GUSMÃO, 1990, p. 38); "as mãos do leitor procuram abrir a sua própria história dividida vindo." (idem, p. 38); "O leitor é um vocativo que está sempre fora de lugar, e assim os disparos dividem-no em figuras precárias que imediatamente confundem os seus contornos num caleidoscópio errado [...]" (ibidem, p. 44).

Consoante a isso, nota-se, no trabalho do poeta, a existência de uma concepção de leitura relacionada com uma construção epistemológica. Para Gusmão, o ato de ler desencadeia um processo de conhecimento, não só de códigos linguísticos como também do grande livro que é o mundo. De certo modo, trata-se de ação solidária, de uma cumplicidade, de uma forma de partilha sensível-cognitiva, de uma conversa humana, ou como nos diz o ensaísta Jorge Fernandes da Silveira, uma espécie de "verso com verso", imagem com imagem, "uma maneira de conversação e/ou de conversão entre sujeitos e objetos de cultura" (SILVEIRA, 2003, p.11 - Grifos do autor). E cultura, além de nos remeter aos comportamentos e às formas de manifestações artísticas e técnicas da humanidade, leva-nos a pensar em cultivo. Ora, por essa perspectiva, através da interação com o poeta e o texto, o leitor transforma sabor em saber, cultiva o gosto e suas habilidades intelectivas. Então, ler é também trabalho cultural, constituição de novos repertórios e desenvolvimento de um olhar cuidadoso para a materialidade laborada. Em "As posições do leitor", seção do livro Dois sóis, a rosa - a arquitectura do mundo (1990), Gusmão nos apresenta um leitor desejoso do saber, "ávido da letra seguinte, ansioso por conhecer" (COELHO, 2001, p. 86) as camadas do palimpsesto poético: "O leitor aprende o que não sabe e sabe essa luz que inicia o seu nascimento desde o fogo antigo até o negro definitivo destas letras.” (GUSMÃO, 1990, p. 36); “Então o leitor [...] subitamente não cessa de aprender, de buscar o nome de um sofrimento que divide em si a luz das águas do céu, [...]"(idem, p. 45); "Aceitemos mesmo que este saber se partilha e que o leitor avance." (ibidem, p. 49).

Segundo Ruy Belo, a poesia pode ser um meio de conhecer a si mesmo e aos outros. Com base nesse ponto de vista, ele defende a importância de uma educação poética, já que a escrita poemática é "uma forma de visão que ensina a ver" (BELO, 2002, p. 290). Embora compreenda que leitores e poetas terão constante necessidade de aperfeiçoamento, de mudanças e de abordagens mais complexas e diversas, Ruy Belo acredita que é importante "aprender a fruir do poema e da beleza que nele se contém" (idem, p. 104) e, possivelmente, a partir dele, desenvolver o diálogo com outros âmbitos culturais. De maneira próxima, Gusmão expõe que ler é "um modo de compreensão" (GUSMÃO, 2010, p. 92) e implica a aprendizagem de códigos e de procedimentos que não são exatamente linguísticos, 
o exercício de uma "imaginação rigorosa” (idem, p. 11) e a partilha de uma tradição, de um patrimônio historicamente construído (ibidem, p. 92).

O conhecimento, que a poesia nos proporciona, conduz o leitor a um possível confronto e, talvez, resistência, porque a aprendizagem é também uma experiência da queda: "O poema ensina a cair/ sobre os vários solos/ [...] como se perde os sentidos numa/ queda de amor" (JORGE, 2008, p. 64). Certamente, por tal motivo, Barthes assegure que o texto de fruição nos põe em estado de perda, de desconforto e nos desestabiliza, "faz vacilar as bases históricas, culturais, psicológicas do leitor, a consistência de seus gostos, de seus valores e de suas lembranças, faz entrar em crise sua relação com a linguagem." (BARTHES, 1987, p. 21). No entanto, na ótica de Gusmão, a crise, a resistência e a insistência são, de alguma forma, propriedades inerentes ao texto vivo, já que ele não se deixa esgotar por um único gesto leitor; ao contrário, apela continuamente para novas leituras: "[...] vais de qualquer modo escrevendo sobre as frases que lês o medo e o ódio, a escolha." (GUSMÃO, 1990, p. 35). Cada poema solicita àquele que lê a reconstrução ou a reinvenção de sentidos. Ao eleger os caminhos para adentrar o espaço textual, "o leitor joga com o vazio, com a casa vazia que incentiva o jogo" (COELHO, 2001, p. 91): "o leitor afasta-se um pouco e sabe que há algo que sempre lhe falta saber." (GUSMÃO, 1990, p. 50).

Através do jogo de presença e ausência, preenchimento e vazio, afetos e fricções, o leitor, paulatinamente, insere-se no corpo verbo-visual do poema e, com o autor, põe-se a escrever, a rasurar, a reconstruir os traços tipográficos, a mobilizá-los e a transformá-los. Ele aprende a olhar para dentro do texto, pois participa da mesma fisicidade que o constitui: “[...] sublinhando, escrevendo em itálico, abrindo parênteses, sempre abrindo a ameaça com a veemente entrega à fascinação que magoa e exalta, à alegria e à desatada miséria." (idem, p. 35); "[...] afasta e aproxima as fronteiras, folheia-as e dobra-as umas sobre as outras, e assim as frases e o país rolam, alteram-se as suas várias camadas, [...]" (ibidem, p. 38); "Saltando de risco em risco, a sua alma diz o texto, variando as entonações, sempre falhada a voz." (ibidem, p. 44); "O leitor escrevendo sabe que alguma coisa o risca como ele risca as frases por cima das quais escreve [...]" (ibidem, p. 51).

A mobilização pelas páginas desencadeia a construção de uma tessitura errática de habitação. O leitor "parte para longes terras" (ibidem, p. 40), desloca-se pelo traçado da escrita, num labirinto de vozes, imagens e tempos, tentando ocupar o espaço sensível e intelectivo do poema. Nessa busca de habitação, o leitor não se fixa, ele assume uma subjetividade viajante que percorre diversos territórios, palavras, composições imagéticas e novos modos de olhar. Na já referida seção "Posições do leitor", Gusmão conduz a figura leitora a diferentes paisagens textuais - a de Clarice Lispector, de Guimarães Rosa, de Virginia Woolf, de Malcom Lowry, de Carlos de Oliveira, de Goethe, de Thomas Mann, de Robert Musil, de Júlio Verne, entre outras -, a paisagens fílmicas - como as de Hitchcock e as de Dreyer -, a lugares discrepantes - Los Angeles, Turquel, palácio de Maximiliano, 
Portela do Francês, Monte Rushmore, Espanha, México, Ítaca, entre outros -, a uma variada geografia - "praias velhíssimas", "terra firme-movediça", "as colinas", "a ilha fatal", "intermináveis ravinas azuis", "uma cadeia de montanhas", entre tantas -, além de oscilar por tempos distintos.

O leitor é também espectador ativo. Aliás, suas mãos ajudam a elaborar os poemas-filmes e, além disso, sua mente torna-se um dispositivo de projeção. Como assinala Fernando Guerreiro, ele é também um "leitor-película", "uma superfície vibrante" que produz suas imagens (GUERREIRO, 2008, p. 104): "Figura luminosa no meio da noite, o leitor irradia pela sala a aventura do livro. Incandesce.” (GUSMÃO, 1990, p. 36); “Pela janela vê a noite posta sobre a mesa. [...] As ondas brilham escuras no cérebro nocturnamente iluminado" (idem, p. 48); “[...] olhando pela janela do comboio que ele no sonho vê como se fosse um filme e não a vida [...]" (ibidem, p. 41). O poeta nos dá a ver um leitor que "sai de si" (COLLOT, 1997, p. 26), projeta-se em seu exterior e adquire o distanciamento necessário para assumir, ao mesmo tempo, a condição de espetáculo e de espectador. Ademais, cada imagem visualizada na lentidão da leitura parece compor fotogramas de uma montagem inusitada: "Em plena biblioteca, os livros cantam, os cavalos invadem, o jardim estremece, as laranjas movem na alegria o frio de janeiro, e a morte vibra alacre pelas figuras do leitor debruçadas pelos múltiplos lagos dos dias e das noites, [...]" (GUSMÃO, 1990, p. 37). No referido excerto, os verbos, cujo campo semântico é o do movimento - "cantam", "invadem", "estremece", "movem", "vibra" - e a estrutura paratática entrecortada sugerem uma estruturação semelhante a de sequências fílmicas montadas. Os personagens desse poema-filme são antropomorfizados e ativados pelas "mãos imaginantes" do leitor. Por meio da angulação que se desloca do close-up - "os livros", "os cavalos", "as laranjas", "a morte” ao plano geral - "o jardim", "múltiplos lagos dos dias e das noites" -, elaboramos mentalmente um filme que se "grava no cérebro e na pele" do texto.

Como se pode observar, as relações entre poesia e outras manifestações artísticas, sobretudo a dinamicidade cinematográfica, são acionadas no ato de leitura. Por esse motivo, Gusmão solicita um leitor-espectador participativo que se mova e se co-mova com o corpo verbo-visual do poema.

O leitor voa letra a letra, do tempo para o tempo. "Voa outro", citando falsamente aquilo que lê: [...]

[...] - percebe o leitor que tudo se mistura e é de vários lados que fala, que soam os disparos. Porque sempre móvel o hipotético ponto de coincidência. E contudo é como se o ruído do motor, a velocidade da deslocação do corpo em movimento, a velocidade da luz e a metamorfose descontínua do território sobrevoado, se tornassem de uma nitidez evidente,

Como a do número finito das gotas de um rio que em flashes sobrepostos se despenhasse

(idem, p. 39) 
Esse leitor-espectador, aceso e movido "pela chama de cada sílaba" que lê (GUSMÃO, 2001, p. 39), é convocado pelo poeta a adentrar a sala escura de sua cinematografia mental, em que as imagens se constroem através de planos variados, pontos de vista, montagens, raccords, movimentos e iluminações. Desse modo, Manuel Gusmão articula seu cinepoiesis e nos apresenta sua ética do olhar, ou seja, o "lento prazer de escrever" (HELDER, 2009, p. 167), de ler e de visualizar o mundo, um conhecimento construído na leitura de-vagar, na "implacável paciência” (GUSMÃO, 1990, p. 108) daquele que monta um cinema verbal.

\section{REFERÊNCIAS BIBLIOGRÁFICAS}

ALVES, Ida. Carlos de Oliveira e Nuno Júdice: poetas, personagens da linguagem. Rio de Janeiro, 2000, 341 f. Tese de Doutorado (Literatura Portuguesa) - Faculdade de Letras, Universidade Federal do Rio de Janeiro UFRJ, Rio de Janeiro, 2000.

BAECQUE, Antoine de. Cinefilia: invenção de um olhar, história de uma cultura 1944-1968. Traduzido por André Telles. São Paulo: Cosac Naify, 2010.

BARTHES, Roland. Aula. Traduzido por Leyla Perrone-Moisés. São Paulo: Cultrix, 1978.

. O prazer do texto. Traduzido por J. Guinsburg. São Paulo: Perspectiva, 1987.

. O rumor da língua. Traduzido por Mario Laranjeira. São Paulo: Martins Fontes, 2004.

BAUDELAIRE, Charles. As Flores do Mal. Traduzido por Ivan Junqueira. Rio de Janeiro: Ed. Nova Fronteira, 2006.

BELO, Ruy. Na senda da poesia. Lisboa: Assírio \& Alvim, 2002.

COELHO, Eduardo Prado. Se o leitor escreve tu escreves. In: e GUSMÃO, Manuel. O leitor escreve para que seja possível. Lisboa: Assírio \& Alvim, 2001.

COLLOT, Michel. La matière-émotion. Paris: Presses Universitaires de France, 1997.

CUNHA, Antônio Geraldo da. Dicionário etimológico da língua portuguesa. 4.ed. Rio de Janeiro: Lexikon, 2010.

EISENSTEIN, Sergei. A forma do filme. Traduzido por Teresa Ottoni. Rio de Janeiro: Zahar, 2002.

FARIA, Daniel. Poesia. Vila Nova de Famalicão: Edições Quasi, 2009. 
GUERREIRO, Fernando. Cinepoiesis: o cinema astral de Manuel Gusmão. In: BUESCU, Helena Carvalhão e BASÍLIO, Kelly Benoudis. Poesia e Arte. A Arte da Poesia. Lisboa: Editorial Caminho, 2008.

GUSMÃO, Manuel. Dois sóis, a rosa - a arquitectura do mundo. Lisboa: Editorial Caminho, 1990.

. Mapas/ o assombro a sombra. Lisboa: Editorial Caminho, 1996.

. Migrações do fogo. Lisboa: Editorial Caminho, 2004.

. A terceira mão. Lisboa: Editorial Caminho, 2007.

. Tatuagem \& palimpsesto: da poesia em alguns poetas e poemas. Lisboa: Assírio \& Alvim, 2010.

. Uma razão dialógica: ensaios sobre literatura, a sua experiência do humano e a sua teoria. Lisboa: Editorial Avante!, 2011.

HELDER, Herberto. Photomaton \& Vox. $3^{\mathrm{a}}$ ed. Lisboa: Assírio \& Alvim, 2006.

. Ofício cantante - poesia completa. Lisboa: Assírio \& Alvim, 2009.

JORGE, Luiza Neto. 19 Recantos e Outros Poemas. Org. Jorge Fernandes da Silveira e Maurício Matos. Rio de Janeiro, 7 Letras, 2008.

OLIVEIRA, Carlos de. Trabalho poético. Lisboa: Assírio \& Alvim, 2003.

RANCIÈRE, Jacques. O espectador emancipado. Traduzido por José Miranda Justo. Lisboa: Orfeu Negro, 2010.

SARAMAGO, José. Ensaio sobre a cegueira. São Paulo: Companhia das Letras, 1995.

SILVEIRA, Jorge Fernandes da. Verso com verso. Coimbra: Angelus Novus, 2003.

Recebido para publicação em 09/08/2015

Aprovado em 28/08/2015

\section{NOTAS}

* Doutora em Literatura Comparada pela Universidade Federal Fluminense. Mestre em Literatura Brasileira e Teoria da Literatura pela mesma universidade.

1 Etimologicamente, o verbo saber vem do latim săpěre e significa tanto "ter sabor; agradar ao paladar; perceber pelo sentido do gosto" quanto "ter inteligência, ciência, conhecimento, informação; conhecer, compreender” (CUNHA, 2010, p. 573). De modo similar, o substantivo sabor, oriundo de săpŏris, deriva do verbo săpĕre e quer dizer "gosto, sabor característico de uma coisa" (CUNHA, 2010, p. 74). 
2 A respeito da obscuridade, Gusmão comenta que é a região de onde nasce os poemas e, por conseguinte, é a desencadeadora do movimento crítico na leitura: "Essa região é feita da mesma matéria obscura a que os antigos chamaram as Musas, que os românticos a inspiração ou a imaginação, que para Rimbaud era o mecanismo da alucinação, que os surrealistas julgaram reconhecer no in-consciente e que é uma região do corpo e das suas almas, onde os gestos e os impulsos verbais se encontram entrelaçados com imagens do mundo e dos humanos nele, agitados por uma energia violenta que estremece no acaso e na certeza, com que caminhamos com as mãos em frente para tactear obstáculos e os ouvidos atentos aos ressaltos." (GUSMÃO, 2011, p. 179).

3 "É o Tédio! - O olhar esquivo à mínima emoção,/ Com patíbulos sonha, ao cachimbo agarrado./ Tu conheces, leitor, o monstro delicado/ - Hipócrita leitor, meu igual, meu irmão!" (Tradução de Ivan Junqueira, 2006, p. 113). 